1 Universidade Federal dos Vales do Jequitinhonha e Mucuri (UFVJM) Faculdade de Medicina do Mucuri - Teófilo Otoni (MG), Brasil.

jandesson.mc@gmail.com

2 Universidade Federal do Espírito Santo (Ufes), Programa de Pós-

Graduação em Saúde

Coletiva - Vitória (ES)

Brasil.

\section{Diabetes Mellitus na mídia impressa: uma análise das matérias nos jornais do Espírito Santo, Brasil}

\author{
Diabetes Mellitus in the printed media: an analysis of the articles in \\ the newspapers of Espírito Santo, Brazil
}

Jandesson Mendes Coqueiro', Adauto Emmerich Oliveira², Túlio Alberto Martins de Figueiredo²

DOI: 10.1590/0103-1104201912119

RESUMO Trata-se de um estudo quantiqualitativo, tendo como objetivo analisar, a partir do referencial teórico da Análise Institucional, as matérias veiculadas sobre o Diabetes Mellitus (DM) pela mídia impressa do Espírito Santo, Brasil. A partir da busca em dois jornais de maior circulação do estado, a saber, 'A Gazeta' e 'A Tribuna', foram identificadas 129 matérias relacionadas ao assunto entre os anos 2014 e 2016. Foi observado, entre outros aspectos, predomínio de matérias em páginas ímpares (51,2\%), uso de fotografias (48,1\%), gênero informativo (78,3\%), omissão do Sistema Único de Saúde (SUS) (92,2\%) e abordagem sobre a prevenção secundária da doença (60,5\%). Percebeu-se grande destaque para matérias relacionadas às novas tecnologias em saúde, tons publicitários e estilo de vida configurado como saudável. Assim, o estudo aponta que a mídia impressa tem importante papel na difusão de informações sobre o DM, entretanto, a relação entre saúde e comunicação no estado do Espírito Santo merece ser revista no tocante a essa doença, visto que observa-se na mídia uma ênfase nas novas tecnologias, muitas vezes, a serviço de interesses empresariais, e uma lacuna no que se diz respeito à valorização do SUS.

PALAVRAS-CHAVE Diabetes Mellitus. Meios de comunicação. Comunicação em saúde. Sistema Único de Saúde.

\begin{abstract}
This is a quanti-qualitative study, aiming to analyze, based on the theoretical reference of the Institutional Analysis, the published articles on Diabetes Mellitus (DM) in the printed media of Espírito Santo, Brazil. From the search of two newspapers with the largest circulation in the state, namely, 'A Gazeta' and 'A Tribuna', 129 articles related to the subject were identified between 2014 and 2016. It was observed, among other aspects, predominance of subjects in odd pages (51.2\%), use of photographs (48.1\%), informational gender (78.3\%), omission of the Unified Health System (SUS) $(92,2 \%)$ and approach on secondary prevention of the disease (60.5\%). Great emphasis was noticed for matters related to the new technologies in health, advertising tones and lifestyle configured as healthy. Thus, the study points out that the printed media has an important role in the dissemination of information about DM, however, the relationship between health and communication in the state of Espirito Santo deserves to be reviewed in relation to this disease, since it is observed in the media an emphasis on new technologies, often, at the service of business interests, and a gap with regards to the valorization of the SUS.
\end{abstract}

KEYWORDS Diabetes Mellitus. Communications media. Health communication. Unified Health System. 


\section{Introdução}

Atualmente, o Diabetes Mellitus (DM), por se configurar como um transtorno metabólico de etiologia distinta, pelo desenvolvimento de complicações e elevadas taxas de morbimortalidade, tem-se configurado como um dos principais problemas de saúde no mundo.

Segundo a Federación Internacional de Diabetes' ${ }^{1}$, em 2017, 425 milhões de pessoas conviviam com o DM. As projeções para 2045 apontam que esse número aumente para 629 milhões de pessoas. No Brasil, no mesmo ano, a projeção é de 12 milhões de pessoas convivendo com o DM.

Ter o diagnóstico estabelecido de DM ocasiona uma relevante repercussão na vida do sujeito, demandando dele, a princípio, ajustamento nos planos subjetivos (significados, identidades) e objetivos (manejo da doença), que se relacionam no jogo permanente de ajustes relacionados ao seu modo de viver ${ }^{\mathbf{2} 3}$.

A relação dos sujeitos adoecidos (ou não) com o DM e suas práticas de cuidado é complexa, pois requer ações de promoção, prevenção e tratamento da doença, e, com isso, verifica-se uma constante disseminação de informações quanto ao estilo de vida e aos comportamentos considerados saudáveis. Essas informações podem ser empreendidas pelos profissionais de saúde, nos momentos das consultas e atividades educativas, mas, também, pela mídia, que se utiliza de dispositivos como televisão e jornais para divulgação de notícias relacionadas à saúde.

Em se tratando da mídia, seus interesses pelos assuntos relacionados à saúde (como o DM) são cada vez mais evidentes. São constantes as matérias de jornais, os programas de televisão e sites com diversas informações sobre dietas, medicamentos e epidemia. Esse fascínio pela saúde exprime-se, também, pela criação de seções fixas dedicadas ao tema, assim como pela prática de contratar profissionais da saúde como especialistas. Os temas de saúde, tendo se tornado relevantes em nossa sociedade, adquirem grande valor-notícia, sendo explicitamente reconhecidos pelos profissionais da área, que alegam ser um dos assuntos de maior demanda por parte dos consumidores de produtos midiáticos ${ }^{4}$.

Vale frisar que a mídia, ao divulgar matérias referentes à saúde, como o DM, pode pautar, aos sujeitos, questões de interesse, o que na Comunicação Social é substrato da Teoria do Agendamento, isto é, a mídia tem a capacidade de colocar em destaque temáticas que se tornam objetos de debates públicos na sociedade em determinado momento; do mesmo modo que a mídia também pode, através do enquadramento, conduzir quais partes da realidade se tornarão visíveis, ou seja, a qual componente de determinado tema ela dará uma evidência maior para o público ${ }^{5}$.

Nesse cenário, verifica-se que quanto menos experiência direta possuem os sujeitos com relação a determinados assuntos, como o DM, maior é sua dependência com a mídia, a fim de compreender e posicionar-se diante das informações e interpretações referentes a esse tema ${ }^{6}$.

As notícias sobre o DM, atualmente, vêm ganhando cada vez mais destaque - reflexo da sua grande incidência e das complexas mudanças na vida de quem passa a ter tal enfermidade. Em um estudo realizado com a finalidade de analisar Doenças Midiaticamente Negligenciadas, foi identificado no estado do Espírito Santo que, entre 5.232 matérias publicadas nos dois jornais de maior circulação do estado, entre 2011 e 2012, o DM ocupou o segundo lugar no ranking, com 433 matérias, evidenciando, portanto, a tradição midiática dessa doença7.

No entanto, essas notícias são divulgadas com as mais variadas perspectivas, disseminando assuntos (medicamentos e alimentação, por exemplo) com uma carga de sentidos que visam a convencer tanto os leitores considerados saudáveis quanto os indivíduos com risco, assim como sujeitos já diagnosticados com a doença, com diversas informações e fortalecimento da produção de necessidades de saúde. Para isso, a mídia utiliza-se de premissas e argumentos implícitos para vender 
notícias e divulgar tecnologias em saúde, a serviço das empresas que, estrategicamente, buscam fomentar mercado de consumidores de produtos e serviços, desde a prevenção até o cuidado com a doença ${ }^{8}$.

Há de se considerar que, mesmo a mídia atuando como um importante dispositivo para divulgação de informações sobre o DM, fazem-se necessárias a problematização, a reflexão e a avaliação dessas matérias quanto à qualidade, à abrangência e à pertinência dos assuntos tratados, bem como de seus desdobramentos na sociedade.

Dessa forma, considerando a pluralidade de assuntos e abordagens midiáticas sobre o DM, este estudo tem como objetivo analisar, a partir do referencial teórico da análise institucional, as matérias veiculadas sobre o DM pela mídia impressa do estado do Espírito Santo, Brasil.

\section{Material e métodos}

Trata-se de um estudo documental de abordagem quantiqualitativa. $\mathrm{O}$ material pesquisado foi composto por todas as matérias relacionadas ao DM veiculadas no período de abril de 2014 a março de 2016, nos jornais 'A Tribuna' e 'A Gazeta'. A escolha desses jornais aconteceu devido ao fato de eles possuírem grande impacto e circulação em todo estado.

Os textos coletados incluíram reportagens, editoriais, entrevistas, colunas, resenhas, cartas de leitores etc. Embora tais textos tenham formatos e tamanhos diferentes, eles foram referidos neste estudo como 'matérias', termo assim utilizado em outro estudo versando sobre comunicação e saúde 9 .

A escolha do período para coleta das matérias correspondeu ao lançamento da Portaria $\mathrm{n}^{\mathrm{o}} 483$, de $1^{\circ}$ de abril de $2014^{10}$, que redefiniu a Rede de Atenção à Saúde das Pessoas com Doenças Crônicas no âmbito do Sistema Único de Saúde (SUS) e estabeleceu as diretrizes para a organização de suas linhas de cuidado, culminando em lapso temporal de grandes investimentos no acesso, acolhimento e na comunicação da atenção aos sujeitos com doenças crônicas.

Embora usualmente denominada como doença crônica, o DM neste estudo foi referido como 'doença de longa duração', uma vez que acompanha a vida dos adoecidos, provocando crises recorrentes, incapacidades e sofrimentos ${ }^{11}$.

A busca das matérias aconteceu junto ao acervo documental do Observatório Saúde na Mídia - Regional Espírito Santo (OSM-ES) -, do Programa de Pós-Graduação em Saúde Coletiva (PPGSC) da Universidade Federal do Espírito Santo (Ufes), no qual essas matérias estavam reunidas em versão Portable Document Format (PDF).

O OSM-ES representa uma iniciativa desenvolvida por meio do convênio de cooperação técnica, firmado, em 2015, entre o PPGSC/Ufes e o Instituto de Comunicação e Informação Científica e Tecnológica em Saúde (Icict) da Fundação Oswaldo Cruz, que, em 2008, fundou o OSM no Rio de Janeiro, tendo como objetivo, entre outros, analisar criticamente os modos pelos quais os meios de comunicação constroem discursivamente os sentidos sobre o SUS e os temas específicos da saúde. Para isso, o OSM-ES encerra um banco de dados com todas as matérias sobre a saúde dos jornais de maior circulação no estado ${ }^{\mathbf{1 2}}$.

Foi realizado um levantamento retrospectivo das matérias que apresentavam em seu conteúdo as palavras-chave diabetes mellitus, diabetes, diabético e diabética. A escolha desses descritores se deu por serem considerados, a partir da leitura preliminar das matérias sobre o assunto, como relevantes para o tema proposto, pois são eles que nomeiam a temática nos meios de comunicação impressos. Foram excluídas as matérias que citavam o DM, mas não tinham o assunto como seu conteúdo principal.

A seleção das matérias foi feita através do Adobe Acrobat DC, que utiliza busca de informações em documentos PDF baseada em descritores estabelecidos sobre a temática. A escolha desse software se deu por ser um programa global gratuito que proporciona 
visualização, impressão e inserção de comentários em documentos PDF com segurança. Além do mais, ele é o único visualizador de PDF que pode abrir e interagir com todos os tipos de conteúdos em PDF, proporcionando uma facilidade para manipulação das matérias dos jornais impressos ${ }^{13}$.

As matérias coletadas foram impressas, e, em seguida, a sua identificação e leitura acurada foram realizadas, procedendo-se à análise do material.

As matérias foram classificadas por dois pesquisadores treinados, seguindo a distribuição temporal, disposição espacial, chamada de primeira página, editoria, espaço, citação do SUS, fontes citadas e nível de prevenção para o DM. As variáveis foram computadas num banco de dados no programa SPSS 21.0 for Windows, e o tratamento desses dados se deu por análise descritiva, visando à caracterização das matérias.

Em seguida, as matérias foram analisadas conforme os referenciais teóricos da Análise Institucional, e o corpus discursivo foi formado pelas matérias que tiveram como fonte os profissionais de saúde, totalizando 45 matérias. A escolha dos profissionais de saúde se deu por considerar que eles conferem credibilidade às notícias sobre saúde na mídia impressa. Sobre a Análise Institucional, trata-se de uma corrente do Movimento Institucionalista, que foi proposta por René Lourau e George Lapassade, no final da década de 1960, na França, e introduzida no Brasil a partir de $1970^{14,15}$. Ela permite a análise das relações de poder e saber que o jogo social mantém com o sistema manifesto e oculto das instituições ${ }^{\mathbf{1 6}, 17}$.

As instituições são árvores de decisões lógicas que regulam as atividades humanas, indicando o que é proibido, permitido e indiferente. Toda instituição compreende um movimento que a gera (instituinte), um resultado (instituído) e um processo (institucionalização). Para realizar concretamente sua função regulamentadora, as instituições materializam-se em organizações e estabelecimentos $^{18}$, como a mídia, por exemplo.
A pesquisa teve autorização da OSM-ES e do Comitê de Ética em Pesquisa da Ufes, sob o registro CAAE 62653016.4.0000.5060.

\section{Resultados e discussão}

\section{Caracterização das matérias}

No período proposto para a pesquisa, foram selecionadas 129 matérias, sendo 61\% ( $\mathrm{n}=79)$ delas publicadas no jornal 'A Tribuna'.

A distribuição temporal das matérias ao longo do período selecionado apontou que, em julho de 2014, houve um pico com 10,1\% $(n=13)$ das matérias, ou seja, foi nesse mês que houve maior número de publicações relacionadas ao DM nos jornais. Março de 2015, com apenas $0,8 \%(n=1)$ das matérias, foi o mês em que o jornal menos divulgou publicações relacionadas ao assunto. As demais publicações variaram entre duas a três matérias por mês.

Com relação à disposição espacial da matéria, houve predominância das páginas ímpares, com $51,2 \%(n=66)$ nos periódicos selecionados. Isso demonstra o destaque que os jornais deram às notícias com DM, pois, na maioria das vezes, as matérias mais relevantes são publicadas nas páginas ímpares, pois são elas que mais atraem a atenção do leitor ${ }^{19}$.

As matérias apresentaram baixo percentual de chamada na primeira página, totalizando $10,1 \%(\mathrm{n}=13)$ das matérias publicadas. Esse critério é importante, pois as chamadas de capa constituem espaço nobre dos jornais, aguçam a curiosidade do leitor e auxiliam-no a decidir por ler mais em busca de detalhes sobre a matéria ${ }^{20}$. Mas, conforme observado neste estudo, as matérias sobre DM tiveram pouco lugar de destaque, quando observadas por essa variável.

No que se refere à frequência de publicação das matérias na editoria dos jornais, prevaleceu a editoria 'Vida', destinada a assuntos relacionados à saúde, $\operatorname{com} 32,6 \%(\mathrm{n}=42)$, seguida da editoria 'Ciência e Tecnologia', reservada 
para divulgação de avanços tecnológicos, com $13,2 \%(n=17)$.

Sobre os elementos de edição, que têm a potência de renovar a forma de ler, conquistar e capturar o leitor, prevaleceram as matérias com apenas fotografias ao longo do texto, totalizando $48,1 \%(\mathrm{n}=62)$.

Quanto ao formato textual, prevaleceram as matérias publicadas com caráter informativo, $78,3 \%$ ( $\mathrm{n}=101)$, seguido pelo formato opinativo $18,7 \%(\mathrm{n}=24)$.

No formato opinativo, a maioria das matérias, $45,8 \%$ ( $n=11$ ), foi classificada como carta de leitor, seguida pelo formato editorial, com $41,6 \%(n=10)$ das matérias.

Com relação à citação do SUS, 92,2\% (n=119) das matérias não fizeram a citação da sigla ou do termo 'SUS'. Característica importante de se observar, pois há de se considerar que a mídia, no geral, não demonstra interesse em explorar os pontos positivos do SUS, visto que existem setores que lucram com a exposição negativa dos serviços públicos de saúde, e a própria sociedade desconhece as ações desse sistema. Destaca-se, também, que nem sempre fazer menção aos serviços públicos de saúde é dar visibilidade ao SUS, pois existem instituições públicas de saúde que ignoram a logomarca (e a sigla) do sistema de saúde em prédios, veículos, uniformes, ofícios e publicações, potencializando a invisibilidade positiva do SUS diante da população ${ }^{\mathbf{2 1}, 22}$.

Uma análise das matérias divulgadas sobre saúde no 'Jornal Nacional', ao longo de 12 meses, por exemplo, constatou que os hospitais públicos com falta de médicos, negligência ou falhas graves eram explicitamente associados pela mídia ao 'Sistema Público de Saúde' ou ao SUS. Já no caso de campanhas de vacinação, por exemplo, com ações de sucesso, o SUS tende a ficar à sombra, e a invisibilidade do sistema era ainda maior em ações de prevenção e promoção da saúde ${ }^{23}$.

Quanto às fontes, prevaleceram as matérias que citaram apenas profissionais de saúde ao longo do texto, com 18,6\% ( $\mathrm{n}=24)$, seguidas de matérias que citavam profissionais de saúde e pesquisadores e/ou pesquisas ao longo do texto, com 9,3\% ( $\mathrm{n}=12)$ das matérias.

No que tange à abordagem das matérias quanto ao DM, 60,5\% ( $\mathrm{n}=78)$ abordavam a prevenção secundária da doença, ou seja, matérias que tratavam do diagnóstico precoce, tratamento imediato e rastreamento e prevenção das complicações, enquanto a prevenção primária - promoção da saúde e proteção específica, como dieta, exercícios físicos, entre outros - correspondia a $16,3 \%(n=21)$ das matérias.

\section{Diabetes Mellitus em pauta: um olhar sob a análise institucional}

O DM, por configurar-se como uma doença de longa duração, possui singularidades na relação dos sujeitos e suas práticas de cuidado em saúde, compreensão com o corpo e as políticas públicas de saúde voltadas para ações de promoção, prevenção e tratamento da doença.

As mudanças nos paradigmas da saúde, que vêm se dando desde o final de 1980, colocam o DM em um foco de produção de relações e valores encarados pela idiossincrasia e particularidade ${ }^{24}$. A doença pode ser comparada a um processo de reconstrução individual por meio da ação sobre o corpo, em prol da boa forma, sendo ela, simultaneamente, física e psicológica ${ }^{25}$.

Pautar a conduta dos indivíduos com o objetivo de conformar o modo de vida com os cuidados do DM (e a prevenção) se tornou uma questão capaz de mobilizar toda transformação na identidade dos sujeitos adoecidos (ou não) ${ }^{\mathbf{2 4}}$. Em meio a todo esse processo, esses indivíduos se veem lançados em um mundo de informações e novas formas de configuração da relação corpo-self na constituição do eu e da sua ligação com o mundo.

Todo esse processo de mudanças e disseminação de informações é fortemente potencializado pela midiatização da sociedade, no âmbito da experiência com a saúde. Frequentemente, a chegada do sujeito ao especialista (profissional de saúde) é motivada pela leitura de textos informativos de 
diferentes características (leigos, científicos ou jornalísticos), provenientes de diversos suportes (impressos, televisivos ou virtuais) ${ }^{4}$. Entretanto, esses textos e informações precisam ser avaliados e discutidos, pois muitas dessas matérias são entremeadas por não ditos.

O não dito, na análise institucional, refere-se às informações que estão omitidas ou deturpadas nos discursos, textos, comportamentos ou outras formas de manifestação. É apontado, constantemente, como fonte de equívocos e conflitos que influenciam a convivência ou, portanto, as causas ou os resultados de um desconhecimento cuja superação se supõe enriquecedora ${ }^{18}$.

Por meio do resgate das matérias sobre o DM, foi possível perceber que a mídia impressa se configura como um agenciamento capaz de divulgar informações dos mais variados sentidos para leitores que vivem ou não com a doença.

Um agenciamento (ou dispositivo) é um artifício que produz inovações e devires, remodela virtualidades e inventa o novo radical. Os agenciadores - como a mídia impressa - "produzem realidades alternativas e revolucionárias que transformam o horizonte considerado do real, do possível e do impossível"18(147).

Sobre esse aspecto, as matérias a respeito do DM, veiculadas na mídia impressa, demonstraram, em seus textos, a produção de realidades alternativas e revolucionárias com relação às práticas de saúde e novas descobertas que podem levar até mesmo à cura da doença, conforme fragmentos a seguir:

Quem tem doença crônica, sonha um dia ouvir a notícia de que pesquisadores descobriram a cura. No caso do diabetes, essa realidade pode não estar tão distante quanto se imaginava. [...] Os testes (da vacina) já estão sendo feitos em humanos e, segundo médicos do Estado, a vacina deve estar no mercado em, no mínimo, cinco anos26(7).

Cura do diabetes tipo 2. Muitas pessoas não sabem, mas o diabetes tipo 2 pode ser revertido com hábitos saudáveis, como perda de peso ${ }^{27(9)}$.
Essas notícias produzem realidades sob um universo de incertezas, como parte da conjuntura social e cultural do mundo contemporâneo. Ao fazer uma relação do aspecto sociocultural ao DM, elas se apropriam de elementos discursivos que constituem as notícias e, implicitamente, produzem sentimentos de esperança ${ }^{8}$.

Através dos elementos que constituem a notícia, bem como a disseminação de imagens e informações, a mídia se envolve ativamente na construção do mundo social, modela e influencia o curso dos acontecimentos, além de criar situações que poderiam não ter existido em sua ausência ${ }^{28}$.

Esses elementos podem ser compreendidos, na perspectiva da Análise Institucional, como analisadores naturais e analisadores artificiais.

Os analisadores naturais são, no caso da mídia, os assuntos que surgem 'espontaneamente' pela própria vida histórico-social-libidinal e natural, como resultado de suas determinações e liberdade ${ }^{18}$. Por exemplo, matérias sobre o diagnóstico do DM na infância e os desdobramentos a partir disso, conforme exposto a seguir:

Diabético, sim. Mas medalhista também [...]. J. V. faz tudo o que gosta, é apaixonado pela natação e está bem longe do cenário de 'fim do mundo' imaginado pela mãe dele quando J., ainda com 5 anos de idade, foi diagnosticado com diabetes tipo 129(37).

Com 1 ano e 5 meses, G. começou a perder peso, urinava em excesso e bebia muito líquido. O pai percebeu que algo estava diferente com o filho e antecipou uma consulta. 'Ele foi direto para UTI, porque estava com a glicose

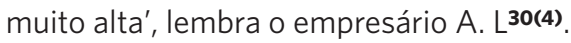

Os analisadores artificiais são dispositivos (no caso, as notícias) implementados pelos analistas institucionais (ou jornalistas) para propiciar a explicitação dos conflitos e sua resolução ${ }^{\mathbf{1 8}}$.

Neste estudo, por exemplo, os analisadores artificiais implementados pela mídia se 
apresentaram pelo destaque das matérias para os assuntos relacionados à difusão de novas tecnologias em saúde, gerando possibilidades de conflitos entre leitores ou, até mesmo, anunciando a possibilidade de resolução dos problemas de saúde, embora tais possibilidades se configurassem como remotas ou de acesso pouco disponível, conforme apresentado a seguir:

Um implante biodegradável capaz de liberar uma medicação dentro do olho de forma gradual, por até seis meses, chegou recentemente ao Brasil e pode ajudar a combater a perda de visão entre pacientes diabéticos ${ }^{31(49)}$.

Novos remédios para perder peso e tratar diabetes. Entre as novidades, estão sensor para medir glicose, pâncreas artificial $[. . .]^{32(2)}$.

Sobre analisadores artificiais exemplificados, nesse caso, pelas inovações tecnológicas, conforme divulgados pelos fragmentos das matérias citadas anteriormente, percebe-se que esse assunto é um aspecto fortemente presente nas matérias de saúde, pois, entre os critérios de noticiabilidade, ou seja, as características que definem a relevância para que um acontecimento seja noticiado, a novidade e a relevância são categorias que justificam o interesse da mídia em divulgar avanços científicos ligados à saúde ${ }^{33}$.

A forte presença da ciência e das tecnologias na mídia é algo observado também por outros estudos, por exemplo, a propaganda farmacêutica como instrumento de elevação das vendas e conquista de mercados versus a política de uso racional de medicamentos ${ }^{34}$; o fenômeno da medicalização e os avanços farmacológicos por meio dos discursos nas capas de duas revistas de grande circulação no Brasil35; e a influência da propaganda na utilização de medicamentos em um grupo de idosos em Aracaju (SE) ${ }^{36}$.

Há de se considerar que a mídia, enquanto veículo responsável por divulgar informações e influenciar ações, tem assumido um papel colaboracionista, prestando subserviência a empresas, no sentido de divulgar inovações tecnológicas, muitas vezes, ainda não acessíveis, e potencializar o aumento de bens e serviços lançados no mercado.

Esse colaboracionismo mídia/empresa configura-se como um atravessamento, ou seja, entrelaçamento e articulação de orientação conservadora (forjada pela mídia), servindo para exploração ou mistificação dos leitores, apresentando-os como necessários e benéficos ${ }^{\mathbf{1 8}}$.

Sobre esse atravessamento, percebe-se que a área da saúde é uma das mais prejudicadas pelo domínio dos interesses comerciais e pela carência de qualificação das informações, oriundas de laboratórios, indústrias farmacêuticas, centros de pesquisa, hospitais, e dos profissionais de saúde, pois todos eles estão interessados em divulgar conhecimentos, seus resultados de pesquisas, seus produtos, suas tecnologias ou a sua excelência na prestação de serviços ${ }^{37}$.

As fontes das matérias, sobretudo aquelas referentes às empresas privadas e aos grupos de pesquisas, conseguem estabelecer pautas ou mesmo ver reproduzidos os seus releases, proclamando resultados e produtos (algumas vezes) sem constatação. Na maior parte dos casos, a matéria assume um tom publicitário tão explícito que pode chegar a incomodar o leitor e trazer indignação àqueles que postulam uma vigilância informativa e uma postura crítica da mídia ${ }^{37}$.

Sobre isso, neste estudo, podemos citar como exemplo uma matéria intitulada 'Mais opções para diabéticos', que, aparentemente, destinava-se a oferecer informações sobre os novos medicamentos utilizados para o gerenciamento do DM. No entanto, o que se percebeu foi o destaque de um medicamento lançado por determinado laboratório:

[...] Três medicamentos modernos foram lançados neste ano e outras substâncias estão em uso. O Laboratório AstaZeneca lançou neste ano o Forxiga, que já chegou ao mercado e está em uso. Esse medicamento, de dose única diária e uso oral, atua diretamente nos 
rins, inibindo uma proteína transportadora da reabsorção de glicose para o sangue ${ }^{38(3)}$.

Cabe ressaltar que a disseminação de informações sobre novas tecnologias, principalmente relacionadas aos avanços farmacêuticos, pode incentivar o consumo de medicamento através da potencialização do marketing, sob o discurso da promoção da saúde e prevenção de doenças, crescendo, dessa forma, a produção e o consumo de grande variedade de mercadorias ${ }^{35}$.

A esse respeito, cita-se como exemplo uma matéria publicada no jornal 'A Tribuna', informando sobre o uso de medicamentos para o DM e a prevenção da obesidade:

Um remédio usado contra diabetes mostrou grande eficácia contra a obesidade [...] a liraglutina age reduzindo o apetite, fazendo com que o alimento passe mais tempo no estômago 32(2).

Percebe-se que, especialmente em se tratando de produtos farmacológicos, existe uma pressão para a incorporação das tecnologias geradas, incentivadas pela criação da demanda por inovações na área da saúde 8 .

A rápida disseminação de informação técnico-científica reconhecida atualmente e o desempenho das empresas multinacionais criam uma demanda local pela inovação (por parte de profissionais de saúde, meios de comunicação e parcelas mais informadas da população), que pressiona ainda mais o sistema de saúde ${ }^{39}$.

Conforme observado, esse processo de difusão sobre as inovações tecnológicas em saúde, através da mídia, envolve interações entre a indústria, o governo e os meios de comunicação, em um processo denominado na análise institucional como 'captura e recuperação’, ou seja, o Estado e os grupos dominantes apropriam-se das singularidades e forças produtivas dos indivíduos, a fim de incorporar essas características nas lógicas acumulativas do Sistema, transformando-as em mercadorias ${ }^{\mathbf{1 8}}$, conforme fragmento da matéria a seguir:

[...] Essa pesquisa está desenvolvendo um pâncreas artificial que será capaz de equilibrar os níveis de insulina no organismo de forma automática, sem que precise furar o dedo ou injetar a insulina no sangue. [...] em pouco tempo sairá o primeiro protótipo. Quem espera pela pesquisa é o aposentado $E$. H., que descobriu o diabetes há 25 anos. 'Tomo insulina há 10 anos. Acho que a tecnologia e essas pesquisas estão em caminho lento, mas estou cheio de esperança'26(7).

Há de se considerar que todo esse debate sobre os avanços das tecnologias de saúde e a mídia vem ganhando destaque nos últimos tempos, devido, principalmente, à mudança no perfil epidemiológico mundial. Se, antes, o saber das ciências da saúde se manifestava nos momentos agudos da doença, hoje, com o desenvolvimento dos novos equipamentos tecnológicos e dos debates no campo da saúde coletiva, o contexto sofreu profundas modificações, buscando-se uma nova compreensão sobre os conceitos em si de saúde e as fronteiras que os separam, pois estar saudável implica noções de qualidade de vida ${ }^{\mathbf{4 0 , 4 1}}$.

$O$ redimensionamento dessas ideias trouxe impactos no processo de subjetivação, pois os sujeitos passaram de seres cotidianamente saudáveis a seres doentes em potencial ou, eventualmente, doentes, cuja condição é ignorada, como no caso de uma glicemia elevada, que ainda não foi diagnosticada pelo exame, mas já está presente. Esse processo referido é denominado a 'lógica do risco'42-45, ou seja, uma ameaça permanente, uma presença constante da doença na sua virtualidade.

A saúde não é só mais um propósito de vida, mas muitas vezes confere sentido a ela, e os profissionais de saúde especialistas são constantemente convocados a ensinar a população a gerenciar os seus corpos e desejos e oferecer orientações na gestão do cotidiano ${ }^{33}$, conforme percebido nos fragmentos das matérias a seguir: 
O endocrinologista $A$. H. afirmou que o paciente com sobrepeso está a um passo da obesidade. 'Obesos, e até pessoas com sobrepeso, têm risco maior de desenvolver problemas como hipertensão arterial, colesterol e diabetes', alertou. [...] As pessoas devem usar produtos que vêm da natureza, os legumes, as verduras e folhas, e mínimo de industrializados, que em geral são mais calóricos e tem mais conservantes e substâncias que provocam uma certa dependência46(2).

Alguns hábitos podem aumentar o risco de ter diabetes tipo 2. 'A população precisa ter conhecimento desses hábitos: obesidade, sedentarismo, tabagismo e má alimentação'. M. N., endocrinologista47(39).

Os textos sobre práticas de privatização da responsabilidade pelo cuidado, por uma governabilidade de si, apresentados pelas matérias ${ }^{\mathbf{4 0}}$ e por fontes de especialistas, são abordados pelas matérias sobre DM. No contexto da sociedade de risco ${ }^{44}$, os textos jornalísticos estimulam os sujeitos a fazerem escolhas individuais mais saudáveis, o que promoveria uma vida mais feliz, com aumento da autoestima e da seguranç $\mathrm{a}^{40}$.

No entanto, com os avanços no campo da epidemiologia, a adoção de juízo de valor favorável ou não às rotinas padronizadas como saudáveis produziu uma regularidade no estilo de vida que possibilita a quantificação do sedentarismo e da vida sem regras e a sua associação a um maior risco de doença ${ }^{42}$. Esse processo trouxe algumas consequências, por exemplo, a moralização dos estilos de vida arriscados, conferindo aos sujeitos que fogem às regras o estigma do pecado e da fraqueza de caráter, e a responsabilidade individual, sem considerar as questões macrossociais que potencializam as condutas de risco em prol dos aspectos relativos exclusivamente ao sujeito ${ }^{\mathbf{4 3}}$, em conformidade com trechos da matéria a seguir:

Estudos apontam que de cada quatro pessoas diagnosticadas com diabetes tipo 2 no Brasil, três não estão com a doença controlada. Essa falta de controle pode ficar ainda pior durante o período de férias, quando é comum dar umas 'escorregadas' na alimentação. A endocrinologista M. P. diz que é possível resistir às tentações do período de descanso. Afinal, você tira férias, mas o diabetes é implacável e não tem recesso ${ }^{\mathbf{4 8}(36)}$.

A partir disso, pode-se perceber, também, que a relação entre as práticas cotidianas e o surgimento de potenciais doenças (como o DM e suas complicações) situa o sujeito como vítima de seus atos, transferindo o controle (o gerenciamento da doença) para ele ${ }^{\mathbf{4 5}}$.

Com relação às notícias sobre práticas cotidianas e o sujeito como vítima de suas ações, cabe mencionar que isso acontece também por conta da individualização da notícia. As matérias proliferam sobre o cuidado, localizando os temas da saúde com mais frequência na vida rotineira dos sujeitos. Embora a dimensão política ainda se faça presente, em especial, nas discussões sobre o sistema público de saúde, o que se observa é o crescimento das matérias sobre cuidados individuais, através de narrativas biográficas que podem aparecer sob forma de testemunhos, denúncias e superação ${ }^{4}$ :

T. M. L. se enquadra no perfil de quem tem entre 35 e 40 de IMC. Com 45 anos, ela fez a cirurgia bariátrica e perdeu 40 quilos. A intervenção foi o marco que fez com que a professora ficasse livre dos remédios do tratamento da diabetes tipo 2. 'A dieta não era mais suficiente para controlar os índices. Tomava remédio todos os dias, mas há 10 anos não tenho mais problema com diabetes', conta $\mathrm{T}^{\mathbf{4 9 ( 4 )} \text {. }}$

A. M. G. e sua nora J. S. S. F. tomaram uma decisão há três semanas: praticar exercícios físicos. [...] J. S. tem a meta de perder 30 kg. Em três semanas ela emagreceu $4 \mathrm{~kg}$. 'Não sou hipertensa e nem tenho diabetes, mas estou me cuidando para evitar que isso aconteça'46(2). 
Essa dimensão individualizante se faz presente tanto nos conteúdos quanto nas estratégias dos textos jornalísticos, pois a experiência pessoal tornou-se uma forma de dar sentido à vivência com a doença. Isso certamente se insere no contexto do mundo individualista, em que o aspecto biográfico é relevante e constitui uma via de entendimento do mundo ${ }^{50,51}$.

Ademais, a mídia é uma das formas de os sujeitos identificarem suas opiniões. Constitui fonte de formação de crenças e atitudes, podendo, dessa maneira, representar o pensamento coletivo da sociedade ${ }^{52}$. Portanto, notícias sobre aspectos relevantes no campo da saúde, em especial, que abordem o DM, devem ser exploradas, para que aconteça reflexão a respeito do que é divulgado, bem como análise da implicação - lugar que o indivíduo ocupa no mundo ${ }^{53}$ - dos sujeitos no processo de comunicação.

\section{Considerações finais}

A mídia tem potência para pautar uma multiplicidade de assuntos sobre os mais diversos contextos em que se insere a sociedade, e, com isso, influencia a formação de opiniões, crenças e condutas sobre diversas temáticas.

Em se tratando do DM, conforme observado neste estudo, não se percebeu negligência: a mídia dá um considerável destaque ao assunto, uma vez que essa doença se caracteriza como endêmica, com aumento de taxas de morbimortalidade, e possui singularidades nas práticas de saúde, para sujeitos adoecidos ou não.

No entanto, apesar do destaque dado ao DM na mídia impressa capixaba, percebeu-se que ambos os jornais estudados se utilizaram de analisadores artificiais para divulgar notícias sobre os avanços tecnológicos a respeito do assunto, incentivando, dessa maneira, a relação entre o consumo e as necessidades de saúde, o que atende mais a interesses empresariais do que à implicação midiática de informar à sociedade. Exemplo concreto disso é o distanciamento que se observa entre o discurso jornalístico e as ações do SUS.

Assim, a relação entre saúde e comunicação no estado do Espírito Santo merece ser revista no tocante ao DM, uma vez que a grande ênfase em matérias sobre novas tecnologias, muitas vezes a serviço dos interesses empresariais, deixa uma lacuna no que diz respeito aos serviços ofertados pelo SUS. Espera-se que os meios de comunicação - importantes ferramentas para a potencialização dos conhecimentos sobre formas de cuidado em saúde e diversas outras temáticas - possam trabalhar em busca da divulgação de assuntos com pertinência, ética e alinhados às necessidades de saúde, com fortalecimento da qualidade de vida da população.

\section{Colaboradores}

Coqueiro JM (0000-0002-5321-5174)* contribuiu substancialmente para a concepção e o planejamento e para a análise e a interpretação dos dados; contribuiu significativamente para a elaboração do rascunho e revisão crítica do conteúdo; e participou da aprovação da versão final do manuscrito. Oliveira AE (0000-0002-9679-8592)* contribuiu significativamente para a revisão crítica do conteúdo; e participou da aprovação da versão final do manuscrito. E Figueiredo TAM (0000-0002-6476-9009)* contribuiu significativamente para a revisão crítica do conteúdo; e participou da aprovação da versão final do manuscrito. 


\section{Referências}

1. Federación Internacional de Diabetes. Atlas de la diabetes de la Federación Internacional de Diabetes. 8. ed. Bruselas: Federación Internacional de Diabetes; 2017.

2. Thoolen BJ, Ridder D, Bensing JM, et al. No Worries, no Impact? A systematic review of emotional, cognitive, and behavioural responses to the diagnosis of Type 2 Diabetes. Health Psychol. Rev. 2008; 2(1):129.

3. Barsaglini RA. As representações sociais e a experiência com o diabetes: um enfoque socioantropológico. Rio de Janeiro: Fiocruz; 2011.

4. Lerner K. Doença, mídia e subjetividade: algumas aproximações teóricas. In: Lerner K, Sacramento I, organizadores. Saúde e Jornalismo: interfaces contemporâneas. Rio de Janeiro: Fiocruz; 2014. p. 151-161.

5. Sousa JP. Elementos de teoria e pesquisa da comunicação e dos media. 2. ed. Porto: Universidade Fernando Pessoa; 2006.

6. Wolf M. Teorias da Comunicação. 5. ed. Lisboa: Editorial Presença; 1999.

7. Cavaca AG, Emerich TB, Vasconcellos-Silva PR, et al. Diseases Neglected by the Media in Espírito Santo, Brazil in 2011-2012. PLOS Negl. Trop. Dis. [internet]. 2016 [acesso em 2017 jun 11]; (10):1-19. Disponível em: https://journals.plos.org/plosntds/article?id=10.1371/ journal.pntd.0004662

8. Guimarães JMM. Paradigmas e trajetórias tecnológicas em saúde: mídia, acesso e o cuidado do diabetes [tese]. Salvador: Universidade Federal da Bahia; 2014. $170 \mathrm{p}$.

9. Rios C, Ortega F, Zorzanelli R, et al. Da invisibilidade à epidemia: a construção narrativa do autismo na mídia impressa brasileira. Interface comun. saúde educ. [internet]. 2015 [acesso em 2017 jun 10]; 19(53):325336. Disponível em: http://www.scielo.br/pdf/icse/ v19n53/1807-5762-icse-1807-576220140146.pdf.
10. Brasil. Ministério da Saúde. Portaria no 483 , de 01 de abril de 2014. Redefine a Rede de Atenção à Saúde das Pessoas com Doenças Crônicas no âmbito do Sistema Único de Saúde (SUS) e estabelece diretrizes para a organização das suas linhas de cuidado. Diário Oficial da União. 2 Abr 2014.

11. Canesqui AM. Adoecimentos de longa duração: análise da literatura publicada em seis periódicos de saúde coletiva/saúde pública. In: Canesqui AM, organizadora. Adoecimentos e sofrimentos de longa duração. 2. ed. São Paulo: Hucitec; 2015. p. 27-69.

12. Cavaca AG, Emerich TB, Lenner K. Observatórios de saúde na mídia: dispositivos de análise crítica em comunicação e saúde. Rev. bras. pesqui. saúde [internet]. 2016 [acesso em 2017 set 18]; 18(3):4-5. Disponível em: http://periodicos.ufes.br/RBPS/article/ view/15705/10869.

13. Adobe Acrobat Reader DC [internet]. Ireland: Adobe Systems Software; 2017 [acesso em 2017 out 10]. Disponível em: https://acrobat.adobe.com/br/pt/acrobat/pdf-reader.html.

14. L’Abbate S. Análise institucional e intervenção: breve referência à gênese social e histórica de uma articulação e sua aplicação à Saúde Coletiva. Mnemosine [internet]. 2012 [acesso em 2017 jul 10]; 8(1):194-219. Disponível em: http://www.mnemosine.com.br/ojs/ index.php/mnemosine/article/view/247/pdf_232.

15. Figueiredo TAM. A Análise Institucional na formação acadêmica da Pós-Graduação em Saúde Coletiva no Espírito Santo. In: L’Abbate S, Mourão ML, Pezzato LM, organizadoras. Análise institucional e Saúde Coletiva. São Paulo: Hucitec; 2013. p. 607-632.

16. Hess R. O movimento da obra de Lourau (1933-2000). In: Altoé S, organizadora. René Lourau: analista institucional em tempo integral. São Paulo: Hucitec; 2004. p. 15-46.

17. Monceau G. Pratique socianalytiques et sócio-clinique institutionnelle. L'Harmattan. 2003; (147):11-33. 
18. Baremblitt G. Compêndio de Análise Institucional e outras correntes: teoria e prática. 6. ed. Belo Horizonte: FGB/IFG; 2012.

19. Folha Online. Círculo Folha [internet]. São Paulo: Empresa Folha da Manhã; 2017 [acesso em 2017 jun 17]. Disponível em: http://wwwl.folha.uol.com.br/ folha/circulo/manual_edicao_p.htm

20. Travassos T. Aspectos funcionais e organizacionais do gênero capa de jornal. Encontros de Vista [internet]. 2011 [acesso em 2017 jul 17]; 8(1):104-120. Disponível em: http://www.encontrosdevista.com.br/ Artigos/10_Tarcisia_Travassos-Aspectos_funcionais_ organizacionais_do_genero_capa_de_jornal.pdf.

21. Xavier C, Narvai PC. A marca invisível do SUS. Ens. Diálogos [internet]. 2015 [acesso em 2017 jun 12]; 1(1):45-49. Disponível em: https://www.abrasco.org. br/site/wp-content/uploads/2016/07/Revista-ENSAIOS-DI\%C3\%81LOGOS_1_Pag-45-a-49.pdf.

22. Lavor A, Dominguez B, Machado K. O SUS que não se vê. Radis. 2011; 1(104): 9-17.

23. Lefèvre F, Caron E. A saúde mediada pela televisão: o caso do Jornal Nacional. In: Sacramento I, organizador. Mediações comunicativas da saúde. Rio de Janeiro: Editora Multifoco; 2017. p. 287-303.

24. Lopes AAF. Donas de casa, mães e avós experimentando o cuidado de si na vida com diabetes. In: Canesqui AM, organizadora. Adoecimentos e sofrimentos de longa duração. 2. ed. São Paulo: Hucitec; 2015. p. $283-314$.

25. Rose N. The politcs of life itself. Teory, Culture and Society. 2001; 18(6):1-30.

26. Martins L. Vacina contra diabetes chega em cinco anos. A Tribuna. 2014 Maio 27; Cad. Cidades: 7 (Col. 3).

27. Octávio P. Cura do diabetes tipo 2. A Tribuna. 2015 Jan 15; Cad. AT2: 9 (Col. 1).
28. Thompson JB. A mídia e a modernidade: uma teoria social da mídia. Petrópolis: Vozes; 2011.

29. Soares L. Diabético sim. Mas medalhista também. A Gazeta. 2014 Ago 26; Cad. Vida: 37 (Col. 1).

30. Magesk L. Sinais de que seu filho tem diabetes. A Gazeta. 2015 Out 25; Cad. Vida \& Família: 4 (Col. 1).

31. São Paulo. Técnica evita perda de visão por diabéticos. A Tribuna. 2014 Jun 11; Cad. Ciência \& Tecnologia: 49 (Col. 1).

32. Spinassé F, Kalle K. Novos remédios para perder peso e tratar diabetes. A Tribuna. 2015 Ago 12; Reportagem especial: 2 (Col. 1).

33. Sodré M. A narração do fato: notas para uma teoria do acontecimento. Petrópolis: Vozes; 2009.

34. Nascimento AC. Propaganda de medicamentos para o grande público: parâmetros conceituais de uma prática produtora de risco. Cienc. Saúde Colet. [internet]. 2010 [acesso em 2017 jun 10]; 15(3): 3423-3431. Disponível em: http://www.scielo.br/scielo.php?script=sci arttext\&pid=S1413-81232010000900017.

35. Ferraz LMRF. Entre remédios e hábitos saudáveis: a medicalização nos discursos de Veja e Época. In: Lerner K, Sacramento I, organizadores. Saúde e Jornalismo: interfaces contemporâneas. Rio de Janeiro: Fiocruz; 2014. p. 219-234.

36. Lyra Jr DP, Neves AS, Cerqueira KS, et al. Influência da propaganda na utilização de medicamentos em um grupo de idosos atendidos em uma unidade básica de saúde em Aracaju (SE, Brasil). Ciênc. Saúde Colet. [internet]. 2010 [acesso em 2017 jun 10]; 15(3): 3497-3505. Disponível em: http://www.scielo.br/pdf/ csc/v15s3/v15s3a24.pdf.

37. Bueno WC. A cobertura de saúde na mídia brasileira: os sintomas de uma doença anunciada. In: Melo JM, Epstein I, Sanches C, et al., organizadores. Mídia e Saúde. Adamantina: UNESCO/UMESP/FAI; 2001. p. 671-689. 
38. Mais opções para diabéticos. A Tribuna. 2014 Set 16; Reportagem especial: 3 (Col. 1).

39. Brasil. Ministério da Saúde. Avaliação de tecnologias em saúde. Ferramentas para a gestão do SUS. Brasília, DF: Ministério da Saúde; 2009.

40. Lerner K, Sacramento I. Apresentação. In: Lerner K, Sacramento I, organizadores. Saúde e Jornalismo: Interfaces contemporâneas. Rio de Janeiro: Fiocruz; 2014. p. 15-31.

41. Vaz P, Pombo M, Fantinato M, et al. O fator de risco na mídia. Interface comun. saúde educ. [internet]. 2007 [acesso em 2017 jun 14]; 11(21):145-153. Disponível em: http://www.scielo.br/pdf/icse/vlln2l/ vlln2la13.pdf.

42. Bagrichevsky M, Castiel LD, Vasconcellos-Silva PR, et al. Discursos sobre comportamento de risco à saúde e moralização da vida cotidiana. Ciênc. Saúde Colet. [internet]. 2010 [acesso em 21 jun 2017]; 15(1):16991708. Disponível em: http://www.scielo.br/pdf/csc/ v15s1/081.pdf.

43. Castiel L, Guilam MCR, Ferreira MS. Correndo o risco: uma introdução aos riscos em saúde. Rio de Janeiro: Fiocruz; 2010.

44. Beck U. Sociedade de risco: rumo a uma outra modernidade. 2. ed. São Paulo: Ed. 34; 2011.

45. Vaz P. As narrativas midiáticas sobre cuidados com a saúde e a construção da subjetividade contemporânea. Logos [internet]. 2006 [acesso em 11 jun 2017]; 25(1):85-95. Disponível em: http://www.logos.uerj. br/PDFS/25/08_Paulo_Vaz.pdf.
46. Proscholdt E, Spinassé F. Maioria já corre o risco de ter pressão alta e diabetes. A Tribuna. 2015 Ago 22; Reportagem especial: 2 (Col. 3).

47. Ermetice MN. Verdades e mitos sobre o diabetes. A Gazeta. 2014 Maio 10; Cad. Vida: 39 (Col. 2).

48. Soares L. Você tira férias. Já o diabetes, não. A Gazeta. 2015 Jul 1; Cad. Vida: 36 (Col. 1).

49. Vérli C. Cirurgia bariátrica controla a diabetes. A Gazeta. 2015 Set 27; Cad. Vida \& Família: 4 (Col. 2).

50. Velho G. Memória, identidade e projeto. In: Velho G. Projeto e metamorfose: antropologia das sociedades complexas. 3. ed. Rio de Janeiro: J. Zahar; 2003. p. 99108.

51. Dumont L. Homo Hierarchicus: o sistema de castas e suas implicações. 2. ed. São Paulo: Edusp; 1997.

52. Ronzani TM, Fernandes AGB, Gebara CFP. Mídia e drogas: análise documental da mídia escrita brasileira sobre o tema entre 1999 e 2003. Ciênc. Saúde Colet. [internet]. 2009 [acesso em 2017 ago 12]; 14(5):17511761. Disponível em: http://www.scielo.br/pdf/csc/ v14n5/16.pdf.

53. Lourau R. Análise institucional e prática de pesquisa. Rio de Janeiro: UERJ; 1993.

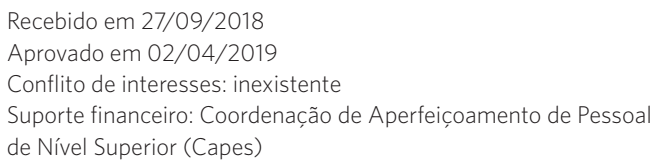

